\title{
The General Court Orders Disclosure of Glyphosate-related Scientific Studies: Tweedale, Hautala, and the Concept of Environmental Information in the Context of Plant Protection Products
}

Case T-716/14, Anthony C Tweedale v European Food Safety Authority, ECLI:EU: $\mathrm{T}: 2019: 141$

Access to documents - Regulation (EC) No 1049/2001 - Documents relating to toxicity studies conducted in connection with the renewal of the approval of the active substance glyphosate - Partial refusal to grant access - Exception relating to the protection of commercial interests - Overriding public interest - Regulation (EC) No 1367/2006 Concept of information relating to emissions into the environment (official headnote)

Case T-329/17, Heidi Hautala and Others v European Food Safety Authority, ECLI:EU: $\mathrm{T}: 2019: 142$

Access to documents - Regulation (EC) No 1049/2001 - Documents relating to carcinogenicity studies conducted in connection with the renewal of the approval of the active substance glyphosate - Partial refusal to grant access - Exception relating to the protection of commercial interests - Overriding public interest Regulation (EC) No 1367/2006 - Concept of information relating to emissions into the environment (official headnote)

Art 4(2) of Regulation (EC) No 1049/2001 of the European Parliament and of the Council of 30 May 2001 regarding public access to European Parliament, Council and Commission documents OJ L 145, 31.5.2001, p 43-48

\footnotetext{
* Amsterdam Centre for European Law and Governance, University of Amsterdam, email: m.morvillo@uva.nl. My research in this field has been supported by a Marie Skłodowska-Curie grant on "The Constitutional Place of Expertise" (CONPLEX), funded under the European Union Horizon2020 research and innovation programme (grant agreement No. 748463). I would like to thank the anonymous reviewer for the comments and suggestions. All mistakes, of course, remain mine.
} 
Art 6(1) of Regulation (EC) No 1367/2006 of the European Parliament and of the Council of 6 September 2006 on the application of the provisions of the Aarhus Convention on Access to Information, Public Participation in Decision-making and Access to Justice in Environmental Matters to Community institutions and bodies OJ L 264, 25.9.2006, p 13-19

\section{FACTS}

Glyphosate is an active substance used in plant protection products, first authorised in 2002 under Council Directive 91/414/EEC. ${ }^{1}$ Originally patented by Monsanto, glyphosate is now produced by several companies operating in the agrochemical sector, and has become the most widely used pesticide worldwide, ${ }^{2}$ not least due to its compatibility with GMO crops.

In 2010, a consortium of producers (Glyphosate Task Force) filed an application for renewal of glyphosate's authorisation to German authorities, under the newly enacted Regulation 1107/2009. ${ }^{3}$ The national competent authority (the German Federal Institute for Risk Assessment) issued a favourable renewal assessment report (RAR), the public version of which was made available by the European Food Safety Authority (EFSA) in March 2014. Pending EFSA's own risk assessment, however, a scientific dispute over glyphosate's safety arose, when the International Agency for Research on Cancer (IARC), a body of the World Health Organisation, concluded that glyphosate was "probably carcinogenic". ${ }^{4}$ EFSA, on the contrary, found the active substance "unlikely to pose carcinogenic hazard to humans", 5 and so did the European Chemicals Agency (ECHA). ${ }^{6}$ Among the various methodological reasons for this divergence, EFSA mentioned the different bodies of data underpinning its assessment and the IARC's: while IARC only relied on published studies, EFSA considered a larger body of evidence, some of which not published and confidential. ${ }^{7}$ The scientific controversy surrounding glyphosate's carcinogenicity, together with public concerns over the independence of the scientific assessments, fuelled a heated political debate (resulting in a European Citizens' Initiative and in the establishment

1 Council Directive 91/414/EEC of 15 July 1991 concerning the placing of plant protection products on the market [1991] OJ L230/1-32.

2 European Parliament Research Service, Authorisation of pesticides in the EU. With a focus on glyphosate (2018) <www.europarl.europa.eu/RegData/etudes/BRIE/2018/614691/EPRS_BRI(2018)614691_EN.pdf> (last accessed 13 June 2019).

3 Regulation (EC) No 1107/2009 of the European Parliament and of the Council of 21 October 2009 concerning the placing of plant protection products on the market and repealing Council Directives 79/117/EEC and 91/414/EEC [2003] OJ L309/1.

4 International Agency for Research on Cancer, Monograph 112 (2015) < monographs.iarc.fr/ENG/Monographs/ vol112/mono112-10.pdf> (last accessed 13 June 2019).

5 European Food Safety Authority, "Conclusion on the peer review of the pesticide risk assessment of the active substance glyphosate" (2015) 13(11) EFSA Journal 4302, at <efsa.onlinelibrary.wiley.com/doi/epdf/10.2903/j.efsa. 2015.4302> (last accessed 13 June 2019).

6 European Chemicals Agency, Committee for Risk Assessment, "Opinion proposing harmonized classification and labelling at EU level of glyphosate" (2017), available at <echa.europa.eu/documents/10162/2f8b5c7f-030f-5d3a-e87e$0262 \mathrm{fb} 392 \mathrm{f} 38>$ (last accessed 5 July 2019).

7 European Food Safety Authority, "EFSA explains risk assessment: Glyphosate" (2015) <www.efsa.europa.eu/ sites/default/files/corporate_publications/files/efsaexplainsglyphosate151112en.pdf > (last accessed 13 June 2019). See also Art 63 of Regulation 1107/2009. 
of a special committee within the European Parliament). It was only in December 2017, after multiple extensions and bargaining at Committee level, that the marketing authorisation for glyphosate was renewed for five years, the minimum according to the 2009 regulation.

In 2014, soon after the RAR publication, Mr Anthony Tweedale, an environmental consultant, filed a request with EFSA for access to documents, pursuant to Regulation 1049/2001 ${ }^{8}$ (Access regulation) and to Regulation 1367/2006 (Aarhus regulation). ${ }^{9}$ The request concerned two "key studies" on the toxicity of glyphosate, used to determine its acceptable daily intake (ADI), based on a laboratory experiment carried out on pregnant rabbits. In particular, Mr Tweedale requested access to "the report written on this animal experiment, and any raw data or other auxiliaries to the experiment", stating that the public summaries of such studies in the RAR were either non-existent or contained no details on the experiment's protocols and results. After having consulted the owners of the requested studies, EFSA first rejected the request ${ }^{10}$ and subsequently granted partial access to the requested studies. ${ }^{11}$ Other parts of the studies, containing information which could undermine the commercial interests of the owners according to Art 63(2) of Regulation 1107/2009, were however found by EFSA to be covered by the exception set out in Art 4(2) of Regulation 1049/2001 (protection of commercial interests and intellectual property rights), since their disclosure would reveal the owners' know-how and commercial strategy. With regard to such information, EFSA stated that the competing public interest in having access to scientific information relating to glyphosate's safety was fully satisfied by the publication of the public version of the RAR. Finally, the requested studies did not constitute information which relates to emissions into the environment for the purposes of Art 6(1) of Regulation 1367/2006.

A parallel request for access to glyphosate-related scientific studies was brought to EFSA in March 2016 by four MEPs (Ms Heidi Hautala and others), pursuant to Regulations 1049/2001 and 1367/2006. With a specific reference to the diverging conclusions reached by EFSA and IARC, the applicants asked the former to disclose all the scientific studies used in the assessment of glyphosate's carcinogenicity. EFSA granted partial access to the 75 unpublished studies (including raw data and findings), with the exception of the parts relating to "material, experimental conditions and methods" and to "results and discussion", which fell under the exception provided by Art 4(2) of Regulation 1049/2001. ${ }^{12}$ According to EFSA, disclosure would seriously harm the commercial and financial interests of the relevant companies, which had invested significant sums to develop those studies. It added that the information disclosed was in the public interest and revealed EFSA's reasoning. EFSA further

\footnotetext{
8 Regulation (EC) No 1049/2001 of the European Parliament and of the Council of 30 May 2001 regarding public access to European Parliament, Council and Commission documents (2001) OJ L 145/43.

9 Regulation (EC) No 1367/2006 of the European Parliament and of the Council of 6 September 2006 on the application of the provisions of the Aarhus Convention on Access to Information, Public Participation in Decisionmaking and Access to Justice in Environmental Matters to Community institutions and bodies (2006) OJ L 264/13.

10 EFSA decision of 30 July 2014.

11 EFSA decision of 16 October 2017.

12 EFSA decision of 7 October 2016.
} 
stated that the requested parts of the studies did not constitute information which "relates to emissions into the environment" for the purposes of Regulation 1367/2006, and that they were not necessary in order to verify the correctness of the scientific risk assessment.

Mr Tweedale and the four MEPs brought two independent actions to the General Court under Art 263 TFEU, seeking the annulment of EFSA's respective negative decisions. The two actions raised identical pleas in law and resulted in "twin judgments". Although not joined by the court, the two cases can be analysed jointly.

\section{JudGMENTS}

The central question in both Tweedale ${ }^{13}$ and Hautala ${ }^{14}$ was whether, in refusing access to the requested studies, EFSA infringed Art 4(2), first indent, of Regulation 1049/2001 and Art 6(1) of Regulation 1367/2006. The former establishes an exception to the general rule of access to European institutions' documents, when disclosure would undermine the protection of "commercial interests of a natural or legal person, including intellectual property", unless there is an overriding public interest in disclosure. The latter qualifies such exception by establishing that, when information relating to emissions into the environment is concerned, "an overriding public interest in disclosure shall be deemed to exist”. In ruling against EFSA, the General Court addresses two main points in law. The first concerns the relationship between Art 4(2), first indent of Regulation 1049/2001 and Art 6(1) of Regulation 1367/2006; the second relates to the concept of emissions into the environment, and, namely, to what constitutes such emissions, and to what constitutes information related to such emissions, in the context of plant protection products.

The Court underscored the ratio underlying Regulation 1049/2001: “openness enables the EU institutions to have greater legitimacy and to be more effective and more accountable to EU citizens in a democratic system and [..], by allowing divergences between various points of view to be openly debated, it also contributes to increasing those citizens' confidence in those institutions". ${ }^{15}$ The principle of openness, and the ensuing right to public access to documents, should therefore be given the widest possible effect. Accordingly, the exceptions to that principle, reflecting the need to take into account competing claims, such as commercial interests and intellectual property, should be interpreted strictly. ${ }^{16}$

The goals pursued by the "Access regulation" are not only shared, but also further qualified by Regulation 1367/2006. By laying down more specific provisions with regard to environmental information, the latter operates as lex specialis, ${ }^{17}$ thus being able to derogate the more general provisions of Regulation 1049/2001. In particular, Art 6(1) of the "Aarhus regulation" establishes a presumption of existence of an

13 Case T-716/14, Anthony C Tweedale v European Food Safety Authority [2019] ECLI:EU:T:2019:141.

14 Case T-329/17, Heidi Hautala and Others v European Food Safety Authority [2019] ECLI:EU:T:2019:142.

15 Anthony C Tweedale v European Food Safety Authority, supra, note 13, para 75; Heidi Hautala and Others $v$ European Food Safety Authority, supra, note 14, para 60, quoting Case C-57/16 P, ClientEarth v Commission [2018] ECLI:EU:C:2018:660, para 75.

16 Case C-673/13 P, Commission v Stichting Greenpeace Nederland and PAN Europe [2016] ECLI:EU:C:2016:889, para 53 .

17 As in Case C-514/11 P, LPN and Finland v Commission [2013] ECLI:EU:C:2013:738, para 79. 
overriding public interest in disclosure: in so doing, it "derogates from the rule requiring the weighing up of the interests laid down in Art 4(2), first indent, of Regulation 1049/ 2001 ". ${ }^{18}$ It is therefore not sufficient to interpret restrictively the exceptions based on those competing interests, which must be waived entirely. In giving direct implementation to the principle of the widest possible access to (environmental) information, the presumption has an absolute nature. As a result, an EU institution cannot refuse access to documents on the basis of the exception relating to the protection of commercial interests of a particular natural or legal person, as EFSA did in the present cases, if such documents contain information which relates to emissions into the environment.

Next, the Court clarified the scope of the concept of information relating to emissions into the environment.

According to the Court of Justice's case law, ${ }^{19}$ the emissions covered by the "Aarhus regulation" are to be understood as those "affecting or likely to affect elements of the environment, in particular air, water and soil". ${ }^{20}$ While the concept does not include purely hypothetical emissions, it does reach beyond emissions that are actually released into the environment, covering also "foreseeable emissions [...] under normal or realistic conditions of use of that product or substance" as envisaged in the marketing authorisation. ${ }^{21}$ While in general the placing on the market of a product does not necessarily entail its release into the environment, the case of plant protection products is peculiar: by their very function, such products, and the active substances contained therein, are meant to be released into the environment, so that their foreseeable emission is in principle all but hypothetic. Glyphosate having been authorised at the European level since 2002, and been widely used, its residues are present in water, plants and food. ${ }^{22}$

The Court turned to examine whether the information contained in the requested studies can be considered information that relates to emission into the environment. Defining the intensity of the link between the requested information and emissions into the environment is crucial for the presumption under Art 6(1). Too vague a link would deprive the exception based on commercial interests of any practical effect, thus jeopardising "the balance which the EU legislature intended to maintain between the objective of transparency and the protection of those interests", and resulting in "a disproportionate interference with the protection of business secrecy". ${ }^{23}$ On the other hand, too high a threshold would undermine the purpose of the regulation and its underlying principles: transparency and openness.

In clarifying the concept of information which "relates to emissions into the environment", the court looked at both its content and its purpose. As to the content,

18 Anthony C Tweedale v European Food Safety Authority, supra, note 13, para 58.

19 Commission v Stichting Greenpeace Nederland and PAN Europe, supra, note 16, paras 73-74; Case C-442/14, Bayer CropScience and Stichting De Bijenstichting [2016], para 81.

20 Anthony C Tweedale v European Food Safety Authority, supra, note 13, para 78; Case T-329/17, Heidi Hautala and Others v European Food Safety Authority, supra, note 14, para 85.

21 ibid, para 80; ibid, para 87.

22 ibid, para 85; ibid, para 92.

23 ibid, para 89; ibid, para 96. 
not only does the concept cover information on "emissions as such (nature, composition, quantity, date and place of those emissions)", as argued by EFSA, but also data concerning "the medium to long-term consequences of those emissions on the environment". ${ }^{24}$ The ratio for this conclusion is to be found in the Court's case law on the interpretation of Art 4(4)(d) of the Aarhus Convention, as transposed by Art 4(2)(d) of Directive 2003/4. ${ }^{25}$ According to such case law, the public interest in disclosure goes beyond the mere understanding of what will be released into the environment, to include specifically "the way in which the environment could be affected by the emissions in question", ${ }^{26}$ and therefore the effects of the emissions.

The purpose of the studies generating the requested information is also relevant in satisfying the test of Art 6(1). In particular, the Court dismissed EFSA's argument according to which the laboratory conditions under which the requested studies were carried out are not comparable with the type and level of exposure that would occur under conditions of normal use. As long as the purpose of the experiments is to assess the effects of actual of foreseeable emissions, held the Court, the material conditions under which such experiments are carried out are in fact irrelevant. As a consequence, only studies aiming at determining the effects of a dose of the relevant substance which is significantly higher than the maximum dose for which the marketing authorisation is granted, ${ }^{27}$ would present a merely hypothetical link with emissions into the environment; this is not the case for studies seeking to establish the substance's properties under the most unfavourable realistic conditions which could possibly occur, ${ }^{28}$ such as those in question.

In both Tweedale and Hautala, the requested studies contain information related to toxicity and carcinogenicity, and, more generally, to the assessment of glyphosate's health effects under the most unfavourable exposure conditions. Access to these studies enables citizens to understand the manner in which human health could be affected by glyphosate being released into the environment. Thus EFSA cannot refuse disclosure on the basis of commercial interests of the data owners.

\section{Comments}

The Court's decisions in Tweedale and Hautala present elements both of novelty and continuity. It is in fact the first time that the Court has qualified toxicity and carcinogenicity studies included in a plant protection product approval dossier as information relating to the environment, thus triggering the absolute presumption of overriding public interests set out by Art 6(1) of Regulation 1367/2006, and setting

\footnotetext{
24 ibid, para 100; ibid, para 107.

25 ibid, paras 93-97; ibid, paras 100-104. According to the Court, on the one hand, the Aarhus Convention has primacy over EU secondary law, which must be interpreted in accordance with it and, on the other hand, Art 4(2)(d) of Directive 2003/4 and Art 6(1) of Regulation 1367 are intended to implement the same article of the Aarhus convention, and should therefore be interpreted consistently.

26 Anthony C Tweedale v European Food Safety Authority, supra, note 13, para 99; Heidi Hautala and Others $v$ European Food Safety Authority, supra, note 14 para 106, quoting Bayer CropScience and Stichting De Bijenstichting, supra, note 19, para 86.

27 ibid, para 111; ibid, para 113.

28 ibid, para 112; ibid, para 114.
} 
aside the exception based on the protection of commercial interests. On a closer examination, however, many of the premises on which the two judgments are rooted can be found in two 2016 cases, Commission v Stichting Greenpeace Nederland and PAN Europe (Greenpeace) ${ }^{29}$ and Bayer CropScience and Stichting De Bijenstichting (Bayer). ${ }^{30}$ Ironically, both relate to the initial authorisation of glyphosate, and in particular to access to studies on residues. Such cases, together with other recent judgments of the Court (notably, ClientEarth $v$ Commission $^{31}$ ), have addressed both the relation between general rule and exceptions in Regulation 1049/2001 and Regulation 1367/2006, and the notion of emission into the environment. ${ }^{32}$

The intensity of the link between the requested information and emissions into the environment is critical in this line of cases. It reflects a balance between openness and the protection of commercial interests. While the General Court in Greenpeace had initially embraced a broad interpretation of this link, defined as "sufficiently direct", 33 the Court of Justice followed a more rigorous approach. In Greenpeace, it rejected such criteria because "that concept may not, in any event, include information containing any kind of link, even direct, to emissions in the environment". ${ }^{34}$ In Bayer, the Court of Justice elaborated on the nature of such link, acknowledging the relevance of the studies' content and purpose. ${ }^{35}$ Read in this context, in Tweedale and Hautala the General Court seems to have aligned its approach with the more rigorous tests outlined in Greenpeace and Bayer in 2016. In its gradual refinement of the scope of the notion of "environmental information" in the context of plant protection products, the Court has been providing the Commission and EFSA with orientation ("guidelines", in the Court's words ${ }^{36}$ ) as to the balance to be struck between openness and commercial interests with regard to different types of information.

Tweedale and Hautala may, however, have further implications. These two cases share with Bayer, Greenpeace, and ClientEarth the same constitutional undertone, since the principle of transparency is connected to the democratic nature of the European decision-making process. The Court sees clearly the potential for enhancing the EU's accountability and, "by allowing divergencies between various points of view to be openly debated" its contribution to strengthening citizens' trust in the institutions. ${ }^{37}$ The Court's principle-oriented reasoning permeates the abovementioned decisions. According to it, transparency and openness serve multiple functions in relation to

\footnotetext{
29 Commission v Stichting Greenpeace Nederland and PAN Europe, supra, note 16.

30 Bayer CropScience and Stichting De Bijenstichting, supra, note 19, on which see E Korkea-aho and P Leino, "Who owns the information held by EU agencies? Weed killers, commercially sensitive information and transparent and participatory governance" (2017) 54 CMLR 1079.

31 ClientEarth $v$ Commission, supra, note 15.

32 In particular interpreting the concept of emissions as encompassing both actual and foreseeable emissions into the environment.

33 Case T-545/11, Stichting Greenpeace Nederland and PAN Europe v Commission [2013] ECLI:EU:T:2013:523, para 53.

34 Commission v Stichting Greenpeace Nederland and PAN Europe, supra, note 16, para 81.

35 Bayer CropScience and Stichting De Bijenstichting, supra, note 19, paras 87-89.

36 Anthony C Tweedale v European Food Safety Authority, supra, note 13, para 93; Heidi Hautala and Others $v$ European Food Safety Authority, supra, note 14, para 100.

37 Anthony C Tweedale v European Food Safety Authority, supra, note 13, para 54; ClientEarth v Commission, supra, note 15 , para 75
} 
environmental matters; more specifically, they relate both to the correctness (ensuring that decisions are justified, ascertaining whether the emissions were correctly assessed, giving the public the opportunity to check) and to the legitimacy of the decisions taken by the institutions. ${ }^{38}$

What is remarkable is the fact that such considerations appear in relation to highly technical matters. While the democratic, trust-enhancing function of transparency is no news for EU courts, ${ }^{39}$ its progressive expansion towards information characterised by high technical complexity is a significant development, especially in a context, such as the EU's, which has often been characterised by an ambiguous relationship between expertise and policy-making. ${ }^{40}$ Countering the assumption according to which the scientific complexity of information results in a restricted role for public participation (and oversight), grounded on the lack of expertise, the Court's approach brings regulatory science back into the domain of public debate. It might be no coincidence that such judicial developments have been taking place on the wake of the glyphosate controversy. This has in fact forcefully exposed the (political, besides regulatory-scientific) tensions involved in a policy field, such as that of plant protection products, characterised by high technical complexity, but also by the presence of strong business interests and public safety concerns. ${ }^{41}$

To conclude, in Tweedale and Hautala the General Court has significantly limited the possibility for institutions to rely on the protection of commercial interests in order to refuse disclosure of environmental information. By adopting a systematic reading of Art 6(1) of Regulation 1367/2006 and of Art 4(2), first indent, of Regulation 1049/ 2001, the Court has confirmed the existence of an overriding public interest in favour of disclosure of environmental information, thus eliminating the need to balance it against the protection of commercial interests. The Court has additionally clarified the meaning of "information relating to emissions into the environment", capable of triggering such presumption, so to include scientific studies aimed at determining the medium- to long-term effects (in this case toxicity and carcinogenicity) of actual or foreseeable emissions of the relevant substance, under realistic conditions of use.

The Court's interpretative approach is informed by the need to give full implementation to the principle of the widest possible availability and dissemination of environmental information. The accountability and participatory concerns trump commercial interests, and the technical complexity of the information at stake. In this principle-oriented interpretative approach, the Court is acting as a catalyst for deliberation. ${ }^{42}$ By "taking transparency seriously" in the context of plant protection

\footnotetext{
38 Anthony C Tweedale v European Food Safety Authority, supra, note 13, para 91; Commission v Stichting Greenpeace Nederland and PAN Europe, supra, note 16, para 80.

39 K Lenaerts, “'In the Union we trust': trust-enhancing principles of community law” (2004) 41 CMLR 317.

40 M Weimer and A de Ruijter, "Regulating Risks in the European Union: The Co-production of Expert and Executive Power" in M Weimer and A de Ruijter (eds), Regulating Risks in the European Union: The Coproduction of Expert and Executive Power (Hart 2017). For a similar development in the field of competition law, see Case C-265/17 P, European Commission v United Parcel Service [2019] ECLI:EU:C:2019:23, paras 53-55.

41 A Arcuri "Glyphosate" in J Hohmann and D Joyce (eds), International Law's Objects (Oxford University Press 2018).

42 J Scott and SP Sturm, "Courts as catalysts: Rethinking the judicial role in new governance" (2007) 13 Columbia Journal of European Law 565.
} 
products, it opens spaces for participation and accountability, and issues normatively motivated guidelines to the decision-makers in these respects. What remains to be seen is whether this relatively young judicial approach will reach beyond the policy field of plant protection products, to embrace other technically complex and politically sensitive areas of EU policy (eg chemicals, medicines, to mention only the most obvious). On the one hand, the legislative framework underpinning the decisions firmly anchors Tweedale and Hautala to the peculiarities of plant protection products, thus undoubtedly limiting its potential for generalisation; on the other hand, however, the constitutional tone of the judgments and the principles invoked might suggest the possibility of generalisation of the Court's reasoning.

Author ORCIDs. (D) Marta Morvillo 0000-0002-1519-742X 